\title{
PEKTUS EKSKAVATUM TEDAVISINDE VACUUM BELL: KONSERVATIF TEDAVIDE ETKILI BIR ARAÇ
}

\author{
Frank-Martin HAECKER \\ Çocuk Cerrahisi Anabilim Dalı, University Children's Hospital, Basel \\ e-posta: frankmartin.haecker@ukbb.ch \\ Çeviri: Nezih Onur ERMERAK \\ Journal of Clinical and Analytical Medicine dergisinin izniyle yayınlanmıştır \\ doi:10.5152/tcb.2011.34
}

Pektus Ekskavatum (PE) en sık görülen göğüs deformitesi malformasyonudur ve yaklaşık her 300 doğumda 1 görülmesiyle en sık görülen majör konjenital anomalilerden biridir (1). Bebeklerin \%85'inden fazlasında defekt daha doğum esnasında farkedilir. Defektin daha geç belirginleşmesi belki Marfan sendromlu hastalarda görülebilir. Geçen yüzyılın sonlarına kadar PE deformitesini düzeltmeye yönelik cerrahi işlemler büyük ölçüde Ravitch tarafından tanımlanan tekniğe dayandırııyordu (2). D. Nuss tarafından (3) 1998 yılında, modifiye Ravitch düzeltme prosedürünün birçok cerrahi yan etkisinden sakınmak için minimal invaziv yöntemle düzeltme (MIRPE) olarak ilk defa yeni bir teknik tanımlandı. Günümüzde MIRPE tekniği kabul görmüş ve sıkça kullanılan bir teknik olarak sunulmaktadır (4-9). Kısa ameliyat süresi, daha küçük insizyonlar ve görece daha az diseksiyon olması MIRPE prosedürünü hem cerrahlar hem de hastalar açısından çekici kılmaktadır, böylece cerrahi tedavi talep eden ve PE'si düzeltilen hastaların sayısında büyük bir artışa sebep olmaktadır. MIRPE prosedürünün yaygın olarak kullanılmasıyla birlikte komplikasyonların niteliğinde ve niceliğinde bir artış gözlenmiştir (4, 6-8, 10-12) (Tablo 1 ve 2).

Herşeyden önce yakın zamanda yapılan çalışmalar ölümcüle yakın komplikasyonların sayısında artış olduğunu göstermektedir (12-18). Birçok PE vakasında, pektus deformitesinin derecesi tam olarak cerrahiye izin vermez bu sebeple hastalara bazı cerrahi dışı tedavi yöntemlerinden yarar sağlanabilmektedir. Bazı hastalar da postoperatif ağrı ve mükemmel olmayan sonuçlar nedeniyle cerrahiye isteksiz olmaktadırlar. Bu nedenlerden dolayı, PE'nin konservatif tedavisi için vacuum bell'in tanıtılması bu alternatif tedaviyi hastalar arasında ilgi odağı haline getirmiştir. Sternumu yükseltmek için vakum uygulanması ilk olarak bundan $100 \mathrm{yıl}$ önce kullanılmıştır (19). Risklere ve operasyon sonrası bazı hastalardaki tatmin etmeyen sonuçlar olmasına rağmen, geride kalan birkaç dekatta vakum tedavisinin terapötik kullanımı açısından çok az gelişme kaydedilmiştir. Bu zaman içinde araçlar geliştirildi ve günümüzde vakum aletleri güçlü kuvvetler uygulayabilmektedir. Bu yöntemi kullanarak elde ettiğimiz erken dönem sonuçları bu yöntemin umut vaat edici olduğunu kanıtlamaktadır (20). Biz burda PE'nin konservatif tedavisi için vacuum bell kullanımı ile ilgili devam etmekde olan tecrübemizi aktarmaktayız. Bu hastaların bir alt grubu olan ilk 34 hastanın daha önceden aktarıldığı unutulmamalıdır (20).

\section{Vacuum Bell}

Göğüs duvarında vakum yaratmak için bir vantuz kullanılır. Hasta el pompası sayesinde atmosferik

Tablo 1. MIRPE prosedürünün intraoperatif komplikasyonları

Perikardiyal yaralanma

Kariyak perforasyon

Kardiyak ritim bozuklukları

Interkostal kasların yaralanması/rüptürü

Tansiyon pnömotoraks

Belirgin kan kaybı

Karaciğer perforasyonu

Diyafram yaralanması/rüptürü 


Tablo 2. MIRPE prosedürünün postoperatif komplikas-
yonları
Pnömotoraks (drenaj?)
Plevral efüzyon(drenaj?)
Pnömoni-atelektazi
Hemotoraks(drenaj?)
Perikardiyal efüzyon( ponksiyon?)
Perikardit
Bar kayması( revizyon gereksinimi?)
Stabilizatörün dislokasyonu (revizyon gereksinimi?)
Yara enfeksiyonu
Gereğinden fazla düzeltme
Bar alerjisi
Cilt erozyonu

basıncın \%15 altına kadar vakum oluşturabilir (Resim 1). Hastanın yaşına göre seçim olanağı sağlayan 3 farklı alet boyutu mevcuttur (Resim 2). Orta boyutun silikon duvar ile güçlendirilmiş ek bir versiyonu mevcuttur (vücut geliştirici tip) ki bu versiyon özellikle küçük ve derin PE'li erişkin hastalar için yapılmıştır. Ayrıca genç kızlar ve bayanlar için uygun olan modeli de mevcuttur. Schier ve Bahr tarafından yapılan pilot çalışmalar (21) aletin sternum ve kostaları işlemden hemen sonra eleve ettiğini göstermiştir.Ek olarak bu elevasyon MIRPE prosedürü esnasında torakoskopik olarak da doğrulanmıştır (Resim 3). Vacuum bell günde iki kez olmak suretiyle en az 30 dakika kullanılmalıdır ve azami olarak da saatlerce kullanılabilir.

Vacuum bell ile konservatif terapi endikasyonları aşağıdakileri içerir:

- Hafif dereceli PE'si mevcut olan hastalar

- Cerrahi tedaviden kaçınan hastalar

- Postoperatif ağrı nedeniyle cerrahi tedaviye isteksiz olan hastalar

- Cerrahi sonrası mükemmel olmayan sonuçlardan korkan hastalar

Metodun kontraendikasyonları osteogenesis imperfecta ve Glisson hastalığı gibi iskelet bozuklukları, vaskulopatiler (Marfan sendromu, abdominal anevrizma), koagülopatiler ve kardiyak problemleri kapsamaktadır. Bu problemleri dışlamak amacıyla tedaviye başlamadan önce standard preoperatif hazırlık protokolü rutin olarak uygulanmaktadır. Sübkütan hematom, peteşiyal kanamalar,dorsalji ve işlem esnasında üst ekstremitelerin geçici parestezisi işlemin komplikasyon ve yan etkileri olarak görülmüştür. Ayrıca nadir olarak da işlem esnasında kot kırıkları görülebilse de bizim serimizde mevcut değildir.

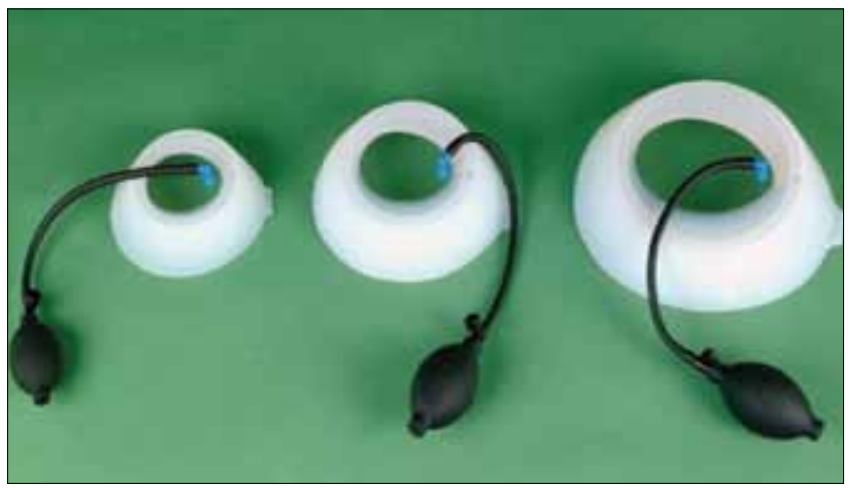

Resim 2. 3 farklı boyutta Vacuum bell' (sol $16 \mathrm{~cm}$,orta 19 $\mathrm{cm}$, sağ $26 \mathrm{~cm}$ yarıçapında)

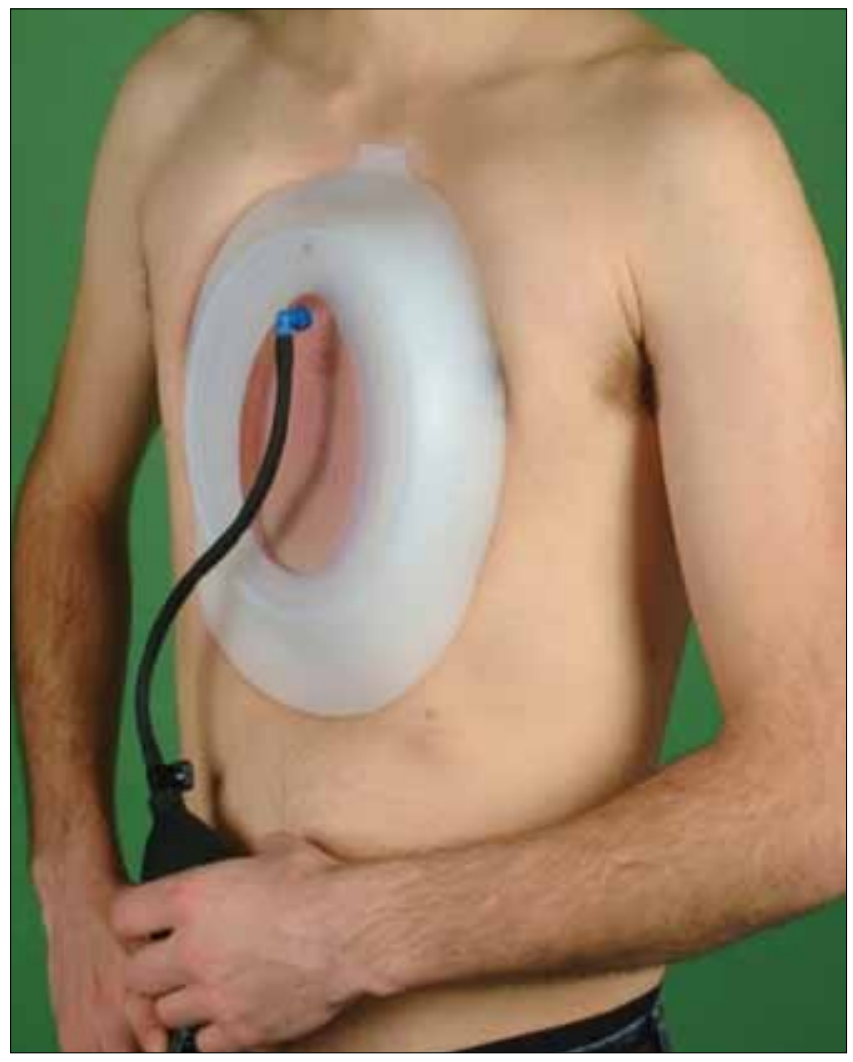

Resim 1. Vacuum bell'in uygulanışı

Yaşları 3 ile 61 (mediyan 17.8 yaş) arasında değişen 93 hasta (77 erken, 16 bayan) vacuum bell ile 1 ile 24 ay (mediyan 10.4 ay) tedavi edilmişlerdir. Prosedüre başlamadan önce uygulanılan standard preoperatif hazırlık; hastanın ve ailesinin özgeçmişinin sorgulanmasını, fizik muayeneyi, ekokardiyografi ve elektrokardiyogram ile kardiyak değerlendirmeyi ve deformitenin fotoğraflanmasını içermektedir. Ek olarak supin pozisyonda PE'nin derinliği ölçülür. Hastalar 3-6 ay aralıklarla fotoğraf ve fizik muayeneyi içeren takiplerle izlenirler.

Vacuum bell'in ilk uygulaması doktor gözetiminde gerçekleştirilir. Günlük uygulama süreleri hastalardan 
hastalara yaygın olarak değişkenlik göstermektedir. Bazı hastalar kullanıcı talimatlarını örnek alarak aleti 30'ar dakikadan günde iki kez uygulamaktadırlar.10 yaşın altındaki hastalar aleti ebeveynlerinin veya bakıcılarının gözetimi altında kullanmaktadırlar. Bazı erişkin hastalar aleti iş saatlerinde de olmak üzere günde 5-6 saat uygulamaktadırlar. Adolesan erkekler aleti her gece 7-8 saat uygulamaktadırlar. Aslında, günlük uygulamanın süresi ve sıklığı hastanın kişisel kararı ve motivasyonuna bağıı olmaktadır.

2006 'dan beri vacuum bell sternumu yükseltmek ve Lorenz introducer ve barlara güvenli geçiş sağlamak amacıyla rutin olarak MIRPE prosedürü esnasında kullanılmaktadır.

İlk 1-5 uygulamada hastaların büyük bir çoğunluğu sternumda orta şiddette bir ağrı ve göğüs içinde rahatsız edici bir baskı tariflediler. Adolesan ve yaşlı hastalarda orta dereceli subkütan hematom oluştu ve birkaç saat içinde kayboldu. Bazı hastalar uygulama
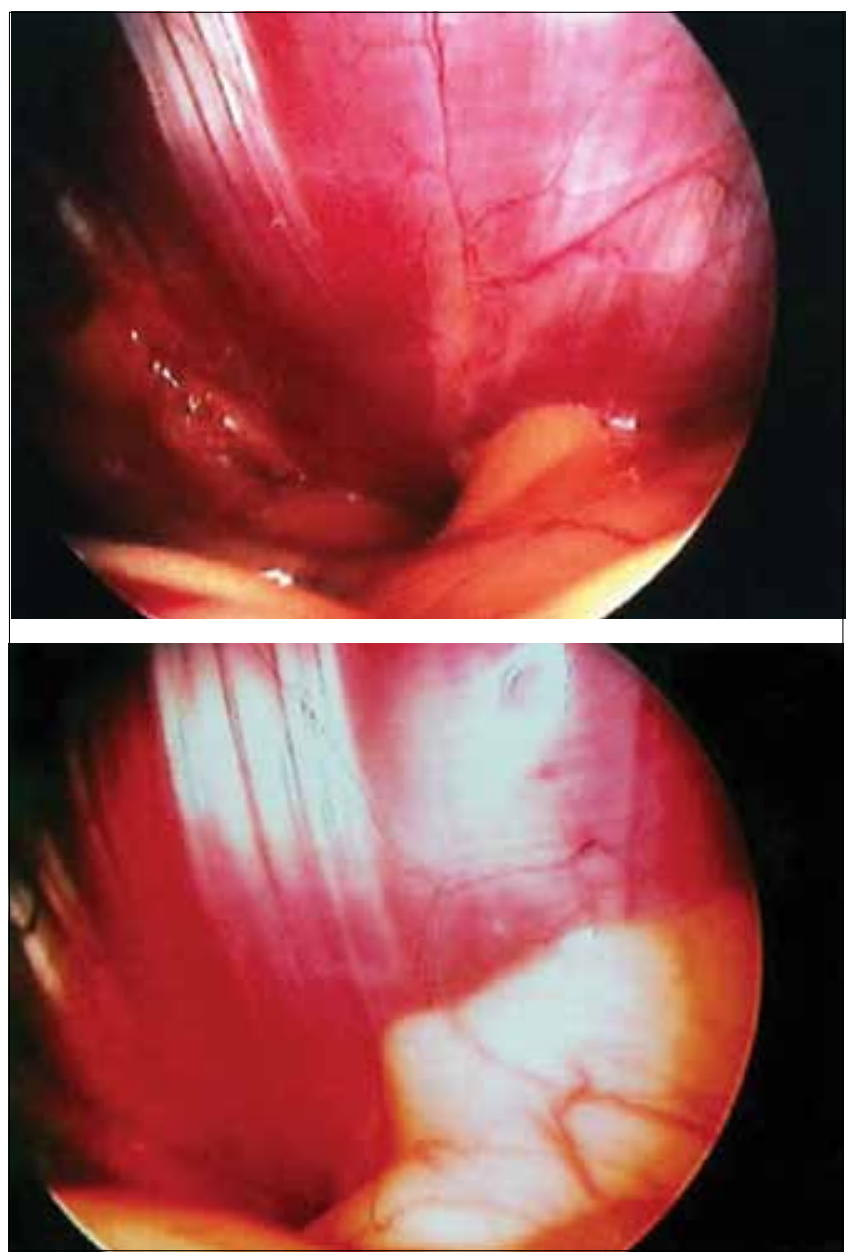

Resim 3. MIRPE prosedürü esnasında vacuum bell'in intraoperatif kullanımı MIRPE prosedürü esnasında retrosternal boşluğun vacuum bell olmadan (sol) ve vacuum bell ile (sağ) görünümü esnasında üst ekstremitelerde rekürren parestezi tariflediler. Bu bulgu uygulama sırasında düşük atmosferik basınç uygulanmasıyla yok oldu.45 yaşında bir hasta tekrarlayan dorsaljiden şikayet etti fakat uygulama süresini kısaltmak bu rahatsızığı önledi. Hiçbir hastada analjezik uygulanması gerekli olmadı. 3 ile 10 yaș arasında çocuklarda vacuum bell uygulanması hiçbir yan etkiye neden olmadı.

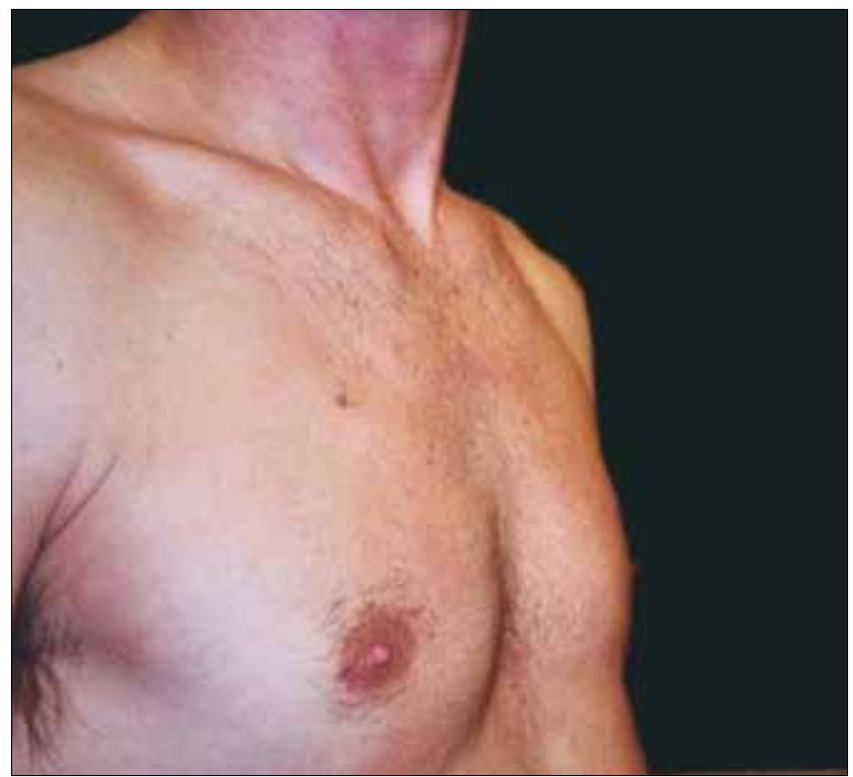

Resim 4a. 45 yaşında hasta, önce (sol;PE derinliği: $2.5 \mathrm{~cm}$ )

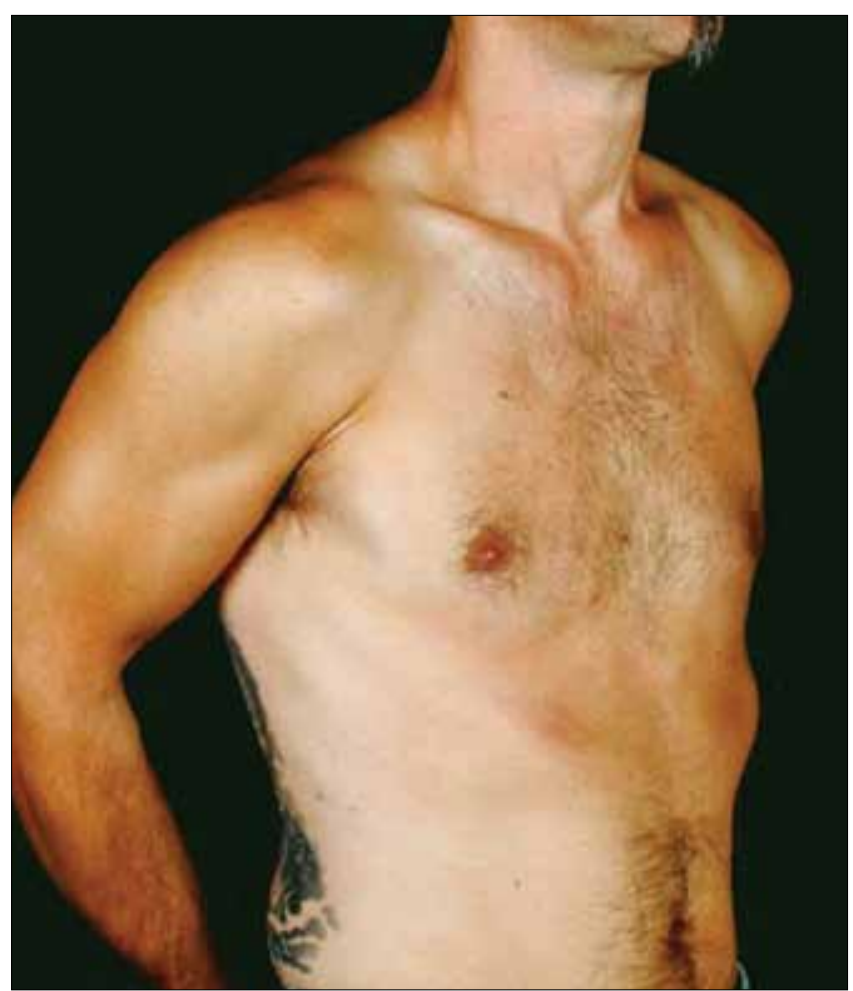

Resim 4b. vacuum bell tedavisi ve 12 ay sonra (sağ: $P E$ derinliği $0.5 \mathrm{~cm}$ ) 


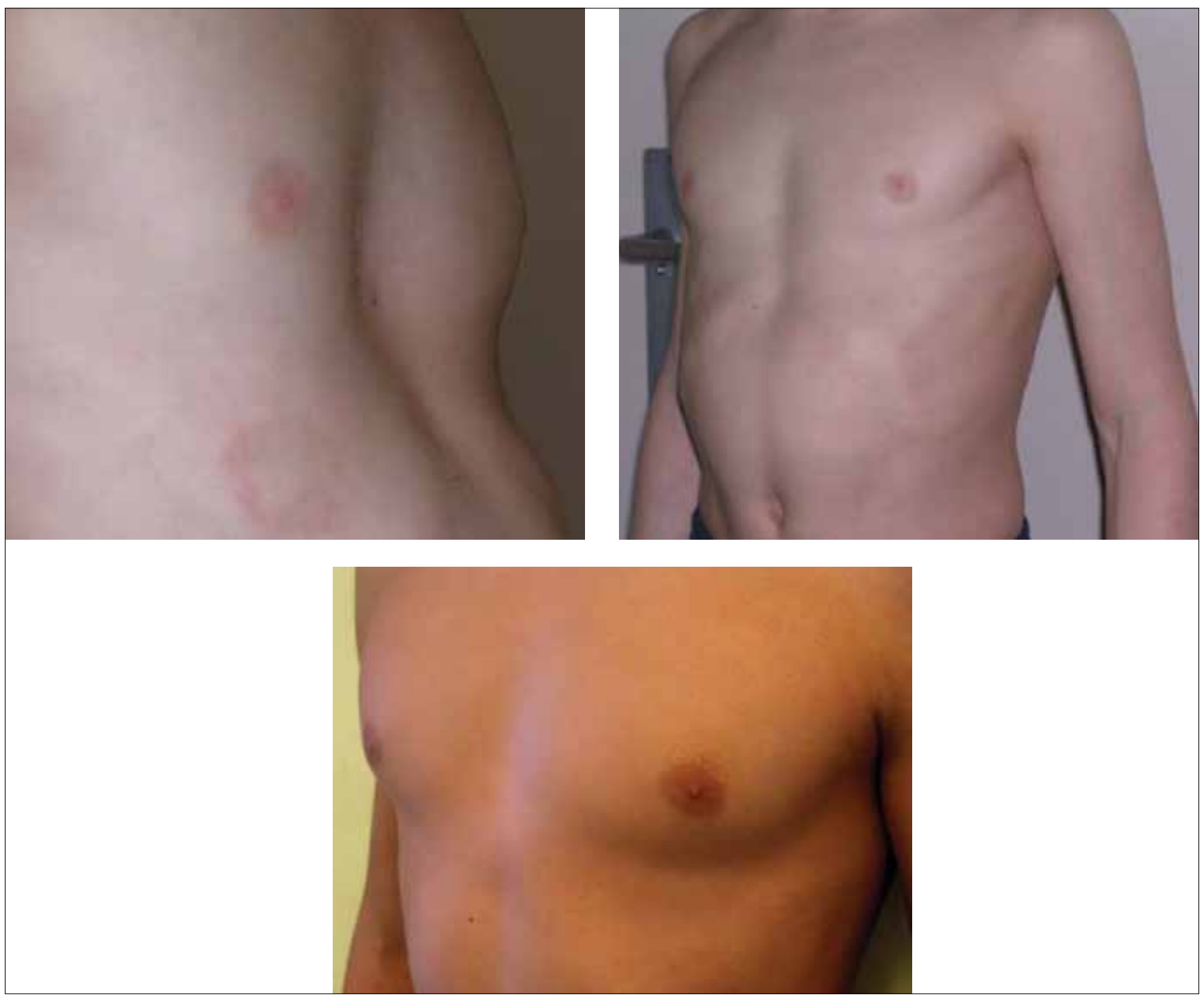

Resim 5. Dokuz yaşında erkek çocuğu, vacuum bell tedavisi öncesi (sol: PE derinliği: $2.8 \mathrm{~cm}$ ) Tedaviden 10 ay sonra (sağ: PE derinliği: $1.6 \mathrm{~cm}$ ) ve tedaviden 36 ay sonra (alt)

Uygulamaya başlandığında hastaların PE derinliği $2 \mathrm{~cm}$ ile $5 \mathrm{~cm}$ arasındaydı.Hastaların 74'ünde (\%69) 3 aylık bir tedavi sonrası $1.5 \mathrm{~cm}$ 'den fazla bir yükselme gözlendi. 9 hastada $(\% 10)$ sternum 18 ay sonra normal seviyeye ulaştı (Resim 4b, b, 5).Tedavi sonrası en uzun takip süresi 5 yıl oldu ve hastaların düzelme başarısı hala kalıcı ve belirgin olarak görülmektedir. Asimetrik PE'li 3 hastada PE derinliği 9 ayda geriledi fakat asimetrisi hala devam ediyordu. 3 hasta postoperatif sonuçtan memnun kalmadı (2 hasta MIRPE sonrası,1 hasta Ravitch prosedürü sonrası) ve vacuum bell tedavisine başladı. 6 hasta ortalama 13.5 ay sonra tedaviyi bıraktı. Bırakma nedenleri tatmin etmeyen sonuçlar (2 hasta) ve motivasyon kaybıydı (4 hasta). Bu 6 hastanın hepsine MIRPE yapıldı. Hepsi sonuçlardan memnundu ve aleti kullanmaları gerektiğinde motivasyonlarını artırmıştı.
Internetin yaygın kullanımıyla,yeni terapötik modalitelerle ilgili bilgiler yalnızca cerrahlar ve pediatristler arasında değil hastalar arasında da çok hızlı bir şekilde ulaşmaktadır. Var olan prosedürlerle cerrahi tedaviyi reddeden belirli bir grup hasta polikliniklerde yeni metodlar arayışıyla karşımıza çıkmaktadır. 1999'dan itibaren departmanımıza başvuran ve MIRPE talebinde bulunan PE hastalarının sayısında artış izlenmektedir. Vakum metodu 1910 gibi erken bir zamanda Lange tarafından kullanılmıştır (19). Bizim hasta grubumuzda kullandığımız vacuum bell kendisi de PE hastası olan bir mühendis tarafından geliştirildi (Klobe $\mathrm{E}$, www.trichterbrust.de). Biz bu metodu 2003'den bu yana kullanmaktayız. Tedavi modalitesinin 5 yıldan fazla uzun süreli kalıcı etkilerinin kanıtları henüz elimizde mevcut değildir. Buna rağmen erken dönem sonuçları etkinliği kanıtlar (20) ve hastaların onayı 
ve uyumlarının iyi olduğu belirtmektedir. Birçok PE vakasında,pektus deformitesinin derecesi tam olarak cerrahiye izin vermez bu sebeple hastalara bazı cerrahi dışı tedavi yöntemlerinden yarar sağlanabilmektedir. Diğer bazı hastalarda postoperatif komplikasyonlar, postoperatif nekaat dönemindeki ağrı ve mükemmel olmayan sonuçların risklerinden dolayı ameliyat olmaya isteksizlerdir. Bu sebepten, PE'nin konservativ tedavisi için vacuum bell'in tanıtımı PE hastaları arasında büyük ilgi uyandırmıştır.

Bir terapötik prosedürün başarısı sadece iyi bir tekniğe değil aynı zamanda uygun endikasyona da bağlıdır.Bizim çalışmamızda simetrik ve hafif PE'li hastarın sonuçları asimetrik ve derin PE'li hastalara kıyasla çok daha başarılı olmuştur. Objektif olarak PE'nin düzelme derecesinin değerlendirilmesi bireyler arasında değişkenlik göstermekteyse de, altı hasta dışında hepsi vaccum bell kulanımından tatminkardı. Bütün hastalarımıza spora ve fizyoterapiye devam etmesi önerildi çünkü, vücut gelişim kontrolünün tedaviye eşlik etmesi sonuca etki eden önemli bir faktördür. Hastaların PE tedavisinde bizzat kendilerinin aktif olarak yer alması tedaviyi sürdürmek açısından motivasyonu artırmaktadır. BT'de gösterildiği üzere, vacuum bell göğsü dakikalar içinde deforme edecek güce sahiptir (21). Bundan dolayı özellike 10 yaşından küçük hastalarda vacuum bell uygulaması çok dikkatli ve bir erişkinin gözetiminde yapılmalıdır.

Vakum oluşturulduğunda sternumun elevasyonu belirginleşir ve belirli bir süre boyunca o şekilde kalır. Bu sayede; vantuz MIRPE prosedürü esnasında kalbe zarar verme riskini azaltmada yardımcı olabilir ki introducerın kalp ve sternum arasında ilerletildiği bu bölüm prosedürün en riskli basamağıdır. Aletin üreticisi vacuum bell için sterlizasyon lisansı alamadığı için, bu ek kullanım alanı klinik bir deneme olarak düşünülmektedir. 2006 yılından beri MIRPE prosedürü esnasında rutin olarak vacuum bell kullanımını hastanemiz hijyenistleri ile işbirliği içinde tecrübe etmekteyiz. Ayrıca, vacuum bell ameliyat için "pre-tedavi" metodu olarak kullanışı olabilir.

Sonuç olarak, vacuum bell bazı PE hastalarının cerrahiye gereksinim duymamasını sağlayabilir. Özellikle simetrik ve hafif $P E$ hastaları bu prosedürden yarar sağlayabilir. Bu uygulama kolay bir yöntemdir ve biz gerek pediatrik gerekse erişkin hastalar tarafından uyum sağlanabildiğini gözlemledik. Fakat; serilerimizdeki takip süresi sadece 5 yılla sınırlı ve bu terapötik aletin yararlıığını incelemek için daha uzun süreli takip çalışmaları gerekmektedir. Ek olarak, MIRPE prosedürü esnasında vacuum bell kullanımı pektus barının girişini kolaylaştırabilir. Her durumda; PE hastalarının tedavisinde bu metod değerli bir yardımcı tedavi olarak görünmektedir.

\section{KAYNAKLAR}

1. Molik KA, Engum SA, Rescorla FJ, West KW, Scherer LR, Grosfeld JL. Pectus excavatum repair: Experience with standard and minimal invasive techniques. J Pediatr Surg 2001;36:324-8.[Crossref]

2. Ravitch MM. The operative treatment of pectus excavatum. Ann Surg 1949;129:429-44.[Crossref]

3. Nuss D, Kelly RE, Croitoru DP, Katz ME. A 10-Year Review of a Minimally Invasive Technique for the Correction of Pectus Excavatum. J Pediatr Surg 1998;33:545-52.[Crossref]

4. Croitoru DP, Kelly RE Jr, Goretsky MJ, Lawson ML, Swoveland B, Nuss D. Experience and Modification Update for the Minimally Invasive Nuss Technique for Pectus Excavatum Repair in 303 Patients. J Pediatr Surg 2002;37:437-45.[Crossref]

5. Hosie S, Sitkiewicz T, Petersen C, et al. Minimally Invasive Repair of Pectus Excavatum - The Nuss Procedure. A European Multicentre Experience. Eur J Pediatr Surg 2002;12:235-8. [Crossref]

6. Nuss D, Croitoru DP, Kelly RE, Goretsky MJ, Nuss KJ, Gustin TS. Review and Discussion of the Complications of Minimally Invasive Pectus Excavatum Repair. Eur J Pediatr Surg 2002;12:230-4. [Crossref]

7. Haecker F-M, Bielek J, von Schweinitz D. Minimally Invasive Repair of Pectus Excavatum (MIRPE): The Basel Experience. Swiss Surgery 2003;9:289-95. [Crossref]

8. Park HJ, Lee SY, Lee CS. Complications Associated with the Nuss Procedure: Analysis of Risk Factors and Suggested Measures for Prevention of Complications. J Pediatr Surg 2004;39:391-5. [Crossref]

9. Dzielicki J, Korlacki W, Janicka I, Dzielicka E. Difficulties and limitations in minimally invasive repair of pectus excavatum - 6 years experiences with Nuss technique. Eur J Cardiothorac Surg 2006;30:801-4. [Crossref]

10. Shin S, Goretsky MJ, Kelly RE, Gustin T, Nuss D. Infectious complications after the Nuss repair in a series of 863 patients. J Pediatr Surg 2007;42:87-92. [Crossref]

11. Berberich T, Haecker F-M, Kehrer B, et al. Postcardiotomy Syndrome after Minimally Invasive Repair of Pectus Excavatum. J Pediatr Surg 2004;39:e1-3. [Crossref]

12. Van Renterghem KM, von Bismarck S, Bax NMA, et al. Should an infected Nuss bar be removed? J Pediatr Surg 2005;40:670-3. [Crossref]

13. Barakat MJ, Morgan JA. Haemopericardium causing cardiac tamponade: a late complication of pectus excavatum repair. Heart 2004;90:e22-3. [Crossref]

14. Barsness K, Bruny J, Janik JS, Partrick DA. Delayed nearfatal hemorrhage after Nuss bar displacement. J Pediatr Surg 2005;40:E5-6. [Crossref]

15. Hoel TN, Rein KA, Svennevig JL. A Life-Threatening Complication of the Nuss-Procedure for Pectus Excavatum. Ann Thorac Surg 2006;81:370-2. [Crossref]

16. Adam LA, Meehan JJ. Erosion of the Nuss bar into the internal mammary artery 4 months after minimally 
invasive repair of pectus excavatum. J Pediatr Surg 2008; 43: 394-7. [Crossref]

17. Gips H, Zaitsev K, Hiss J. Cardiac perforation by a pectus bar after surgical correction of pectus excavatum: case report and review of the literature. Pediatr Surg Int 2008;24:617-20. [Crossref]

18. Haecker F-M, Berberich T, Mayr J, Gambazzi F. Nearfatal bleeding after transmyocardial ventricle lesion during removal of the pectus bar after the Nuss procedure. $J$ Thorac Cardiovasc Surg 2009;138:1240-1. [Crossref]
19. Lange F. Thoraxdeformitäten. In: Pfaundler M, Schlossmann A (editors): Handbuch der Kinderheilkunde, Vol V. Chirurgie und Orthopädie im Kindesalter. Leipzig, FCW Vogel 1910: 157.

20. Haecker FM, Mayr J. The vacuum bell for treatment of pectus excavatum: an alternative to surgical correction? Eur J Cardiothorac Surg 2006;29:557-61. [Crossref]

21. Schier F, Bahr M, Klobe E. The vacuum chest wall lifter: an innovative, nonsurgical addition to the management of pectus excavatum. J Pediatr Surg 2005;40:496-500. [Crossref] 